\title{
Davis, Chris. 2019. Hungarian Religion, Romanian Blood: A Minority Struggle for National Belonging, 1920-1945. Madison, Wisconsin: University of Wisconsin Press. 249 pp.
}

\author{
Reviewed by Călin Cotoi, ${ }^{*}$ University of Bucharest
}

Hungarian Religion, Romanian Blood is a book about the Csangos of the Moldavian region of Eastern Romania, a small religious and ethnic minority living in a remote part of a borderland region in Eastern Europe. Nevertheless, it is far from a classical historical or ethnographic monograph promising to unveil a neglected ethnic identity. Instead, from the very beginning of his book, Chris Davis draws our attention to the ways in which people are made up by sciences, discourses, and politics, and to the "elasticity of ethnic and national identities." It is "the science (and scientism), and always the graphos, the writing," that tells us how identities are distributed historically and socially (xi).

The argument of Davis's book runs on three layers. The first one is a detailed history of the demographically, ethnographically, and nationally "enigmatic" group of Csangos from the Moldavian region of Eastern Romania. The author does not try to discover the "true" identity or origin of this structurally in-between Roman-Catholic population, but rather the historical conditions of possibility for its emergence. That is why the discussion can switch into another, larger frame (the second layer of the three I have discerned), as the author investigates this case study as some kind of microhistorical "exceptional normal" that offers a window into the social, political, and demographic transformation of twentieth-century East-Central Europe. Thus, the Csangos are used, through the careful taking apart of the mechanism through which they have been "made," as a privileged entry point into a more theoretical discussion about the creation of collective political identities at local, national, and transnational levels, through alliances, antagonisms, and even open conflict. I envisage this as the third layer of Chris Davis' argument, and the most interesting one, as such.

The book starts with demography. Counting the Csango minority has been a highly political endeavor for this minority that is caught between the Hungarian and Romanian nations and their respective identity-building projects. The question of who counts who and to what avail is one of the main common threads of this book. Minorities, especially groups like the Csangos, where there was no clear-cut ethnic and state-sanctioned cultural identity, and where religious affiliation usually trumped ethnic or racial ones, were particularly troubling for contemporary national homogenizing projects. In the end, "numbers in a column meant more than all the

*calin.cotoi@sas.unibuc.ro

(cc) BY

ULLS D-Serbe
New articles in this journal are licensed under a Creative Commons Attribution 4.0 International License.

This journal is published by the University Library System of the University of Pittsburgh as part of its D-Scribe Digital Publishing Program and is cosponsored by the University of Pittsburgh Press 
treatises on the ethnic substance that defines a nation, or a nation's soul or character, which both Romanian and Hungarian ideologues peddled in the interwar period" (21).

The Csangos were unmistakably Catholic in a country that, at least after WWI, defined itself more and more as Orthodox. The second chapter peruses the emergence of the CatholicOrthodox polemics in Greater Romania, and how the Csangos got caught in, but also provided a privileged field, for the debates on the articulation between confession and nationality. Can a Catholic be an authentic Romanian, or just a "good" one, meaning just a loyal citizen but not spiritually part of Romanianess? For the Csangos and their local clerical elites this was not only a theoretical question but rather an existential choice.

The third chapter, "The Profane: A True Science of the Nation and People," balances the Romanian and Hungarian scientific discourses on nation, de-nationalization, re-nationalization, ethnicity and race. On the one hand, a group of Hungarian ethnographers, linguists, and statisticians tried to save the archaic Hungarian essence persistent in Moldavia, and mounted an "ideological, political, and historiographical resistance against the Romanianization efforts of the Csango clergy in Moldavia during the early 1940s" (86). On the other hand, the local Catholic clergy, attempting to prove, once and for all, the Romanianess of the Csangos, became frantic in the face of plans for population-exchange between Romania and Hungary. They had to demonstrate that Csangos were Romanians in order to protect them, and they did that by using all the accepted scientific languages and discursive devices available in a transnational environment stressing ethnic and even racial purity.

The last three chapters in Davis's book ("Certifiably Romanian," "Resettlement 'Home'," and "The Cry of Blood") introduce a change of rhythm. If the large sweeps over the Romanian and Hungarian debates around national identity and religion were inevitably a bit cursory, in this second part of the book the author shows his deep understanding of the history of the region, and he illuminates the connections between the fate of Csangos and the larger problems of nation building, survival, and religious politics. This enables the Csango case to be shown in all its historical strangeness and larger implications - demographically, culturally, and nationally.

The author builds on a variety of theoretical traditions coming from history, anthropology, political science, and sociology. The analysis of the process of the "making of Csangos," which recalls Ian Hacking's version of Foucauldian investigations into the "making of people," is innovative and powerful as an analytical instrument. There was a flurry of documents, classifications, and certificates that accompanied the Csangos' entrance into the hyper-nationalized world of interwar and World War II Central and Eastern Europe. Jane Caplan's work, combined with the already classical analyses of James C. Scott on "legibility" and "weapons of the weak" coming from political science and anthropology, become important theoretical tools that are wielded in a precise historiographical way to disentangle much of the conundrum of Csango "identity." Here Davis deals in an enlightening way with the problematic concepts of "identity," "nationality," and "ethnicity" by projecting them as material practices and protocols of identification.

The main strength of Davis's book comes from its layered interdisciplinary examination that makes many muted or stabilized historical and political entities — state, nation, religion, and ethnicity - appear in a dynamic and to-date not-yet-achieved form. Through a marginal case we are sometimes able to see the ways in which these modern institutions and discourses create both themselves and the people(s) they are supposed to define, serve and represent. The author tells a fascinating story of one of Europe's "people without history," as its members are oftentimes forced to deal with the ambiguity of nationalized forms of modernity. 
The Csango minority has been ethnographically, demographically and politically created at the troubled intersection of two antagonistically defined nationalizing projects - the Romanian and the Hungarian. Any research on the Csangos has to navigate complicated political and epistemological waters. Most of the books and texts published on the topic of the Csangos are quite partisan and, at least implicitly, nationalistic - with some notable exceptions. They try, directly or indirectly, to prove the Hungarian or Romanian true ethnic origin of this population. This is something that Chris Davis programmatically avoids, making, in my view, the right theoretical, historical, and rhetorical decisions.

This book proposes, based on an international and transnational case-study, to make larger and more comprehensive arguments about Central and Eastern European nation-building (and religious-identity building) mechanisms. It is akin to books such as Holly Case's Between States: The Transylvanian Question and the European Idea During WWII (2009), Maria Bucur's Eugenics and Modernization in Interwar Romania (2002), Vladimir Solonari's Purifying the Nation: Population Exchange and Ethnic Cleansing in Nazi-Allied Romania, and Marius Turda' s books about the biological re-codifying of Central European nationalisms. Chris Davis's study, by its focus on the Csango minority, may look, at first glance, less inclusive than these books. However, I argue that it is not the case, as the author is able to strike a balance between the details of his case study and general arguments, so it stands out by taking its own less traveled path. 